\title{
A trajetória da natureza na geografia escolar brasileira: permanências e mudanças
}

\author{
The trajectory of nature in brazilian school geography: permanences \\ and changes
}

\author{
Dayane Galdino Brito'
}

\section{RESUMO}

A partir da perspectiva teórica da história das disciplinas escolares, buscou-se compreender o percurso histórico do ensino da natureza, enquanto uma dimensão do espaço geográfico, na Geografia Escolar brasileira. A metodologia utilizada foi à revisão bibliográfica. Identificou-se que os conteúdos relacionados à natureza sempre estiveram presentes na Geografia Escolar, assumindo diferentes concepções em cada período: nomenclaturas de "acidentes geográficos"; base para sobreposição das atividades humanas; reduzida a recursos naturais; como primeira e segunda natureza. Estas concepções, por vezes, coexistem no contexto atual, por meio da prática pedagógica do professor e nos materiais didáticos. Na atualidade, as discussões acadêmicas do ensino de Geografia e as políticas curriculares (BNCC), concebem que o ensino dos componentes físico-naturais do espaço geográfico deve estar vinculado à relevância social e à compreensão dos problemas ambientais resultantes da interação entre a indissociabilidade dos elementos formadores do Planeta e o atual estágio intervenção técnica da sociedade, a partir da realidade local dos alunos. Portanto, constitui um desafio à formação do professor de Geografia a superação das permanências no ensino dos componentes físico-naturais como a fragmentação do conhecimento, definições prontas, desarticulados das questões sociais e da vivência dos alunos, dentre outras, que inviabilizam a formação para a cidadania.

Palavras-chave: Ensino; Geografia Acadêmica; Geografia Escolar; Natureza

\section{ABSTRACT}

From the theoretical perspective of the history of school disciplines, sought to understand the historical path of nature teaching, while a dimension of geographical space, in Brazilian School Geography. The methodology used was the bibliographic review. It was identified that the contents related to nature has always been present in School Geography, assuming different conceptions in each period: nomenclatures of "geographical accidents"; basis for overlapping human activities; reduced to natural resources; as first and second nature. These conceptions sometimes coexist today, through the teacher's pedagogical practice and teaching materials. Today, academic discussions of geography teaching and curriculum policies (BNCC) conceive that the teaching of the physico-natural components of the geographical spaces hould be linked to the social relevance, through understanding environmental problems resulting from the interaction between the indissociability of the planet's forming elements and the current stage technical intervention of society, from the local reality of students. Therefore, it is a challenge to the formation of the Geography teacher the overcoming the 'Mestranda no Programa de Pós-Graduação em Geografia, Universidade Federal da Paraíba, João Pessoa, PB. E-mail: dayanegaldinobrito2011@hotmail.com ORCID: https://orcid.org/0000-0001-7987-2802 
permanence in the teaching of natural-physical components as the fragmentation of knowledge, ready settings, disjointed from social issues and the experience of students, among others, that make it impossible to training for citizenship.

Keywords: Teaching; Academic Geography; School Geography; Nature

\section{INTRODUÇÃO}

$\mathrm{Na}$ atualidade, a questão ambiental perpassa interesses sociais, políticos, culturais e econômicos em múltiplas escalas. A poluição das águas, alterações microclimáticas, áreas de risco à inundação e a deslizamento, disposição de resíduos sólidos, dentre outros, são processos de degradação da natureza, resultantes de relações econômicas que afetam, sobretudo, a qualidade de vida dos cidadãos. Torna-se necessário o seu enfrentamento, demandando a cooperação entre os segmentos da sociedade.

A Geografia, como uma disciplina escolar voltada à formação para a cidadania, contribui no esclarecimento da gênese de tais problemáticas, pois o espaço geográfico, seu objeto de estudo, expressa a articulação entre natureza e sociedade (SUERTEGARAY, 2010). Com isso, práticas de ensino pautadas no conceito de ambiente pressupõe o sujeito e seu entorno produzido pela relação entre os aspectos naturais e sociais, fundamentando-se a prática social e política. De modo que os indivíduos possam interferir e transformar sua realidade vivida. Assim, ao ensinar aos alunos os componentes físico-naturais:

[...] deve-se ter o objetivo de formar um conceito crítico de ambiente que se destaca na sua dimensão social, sua dimensão ética e política que propicia a identificação dos problemas ambientais e de sujeitos sociais específicos com níveis de responsabilidade diferentes em relação a esses problemas. (CAVALCANTI, 2010, p. 380).

No entanto, há problemáticas no ensino de conteúdos relacionados aos componentes da natureza como, por exemplo, clima, solos, relevo, água, vegetação e rochas. Sendo recorrente, na Educação Básica, práticas pedagógicas mnemônicas, descontextualizadas do lugar de vivência, dissociadas das relações sociais e a fragmentação dos conteúdos (MORAIS, 2011; AFONSO, 2015). Logo, 
não são mobilizados para a compreensão dos fenômenos geográficos e, por sua vez, não se demonstra a relevância social no ensino, tornando-se desinteressante aos discentes. Mas, o que explica a reprodução dessas práticas pelos professores, visto que contribuem negativamente para o ensino da disciplina?

Ao reconstituir a trajetória da Geografia Escolar, é possível entender as permanências, que prejudicam as contribuições à formação cidadã no ensino dos componentes físico-naturais. Este exercício é fundamental ao professor de Geografia, em formação inicial e continuada, a fim de que entenda a gênese dessas problemáticas na cultura escolar. De modo que, assim, planeje suas aulas com consciência, autonomia e autoria, em coerência com as demandas contemporâneas.

Esta discussão se pauta na perspectiva teórica da história das disciplinas escolares. Segundo Chervel (1990), as disciplinas escolares constituem conhecimentos autônomos produzidos, ao longo de suas respectivas trajetórias no interior do espaço escolar, a partir da interação de diversos agentes, desde o Estado até os professores, alunos e a comunidade escolar. Assim, as disciplinas escolares são passíveis de mudanças e permanências, podendo ser delimitados períodos históricos para seu entendimento.

Desse modo, a Geografia Escolar dispõe de certa autonomia em relação à Geografia Acadêmica, embora mantenha uma relação intrínseca, não configurando uma transposição didática, isto é, uma vulgarização do conhecimento produzido em nível acadêmico. Para se compreender como se deu sua construção e seus efeitos na atualidade, deve-se analisar “[...] a relação entre a escola e a academia, admitindo que a relação entre essas duas instituições se configura por trocas, e não somente por determinações da segunda à primeira [...]" (ALBUQUERQUE, 2011, p. 20).

A partir da perspectiva teórica da história das disciplinas escolares, buscouse compreender o percurso histórico da Geografia como disciplina escolar, com ênfase no ensino da natureza. Como objetivos específicos, analisar as mediações 
entre Geografia Acadêmica e Geografia Escolar; identificar as diferentes concepções de natureza; e, por fim, estabelecer as permanências, as mudanças e as demandas contemporâneas na abordagem doa conteúdos da natureza na Geografia Escolar.

Para tanto, utilizou-se como metodologia a revisão bibliográfica. Para análise das transformações epistemológicas e didáticas, considerar-se-á, com base em Rocha (1996; 2000a), Albuquerque (2005), Pessoa (2007), Suertegaray (2018), a seguinte periodização: Geografia Escolar Clássica, Geografia Escolar Moderna, Geografia Escolar Crítica, Geografia Escolar no contexto dos Parâmetros Curriculares Nacionais e, por fim, as demandas contemporâneas representadas pela Base Nacional Comum Curricular e os debates no campo da Didática da Geografia.

\section{A NATUREZA NA GEOGRAFIA ESCOLAR CLÁSSICA}

A Geografia brasileira se inicia com a sua dimensão escolar, no Período Colonial. Tendo o sistema formal de ensino organizado pelos Jesuítas, normatizado na Ratio Studiorum, que consistia um plano de organização pedagógica e administrativa das instituições Jesuíticas em todo o mundo. Nesse contexto, a Geografia não era uma disciplina escolar autônoma. Contudo, os saberes geográficos eram mobilizados na prática do eruditio, ou seja, subsidiavam a compreensão das obras literárias das disciplinas dominantes, como o latim e o grego. Ademais, eram abordados ensinamentos sobre a Terra, em conexão com os conhecimentos da astronomia, da cosmografia, da cartografia e da geometria (ROCHA, 2000a).

A Geografia elaborada na Antiguidade foi apropriada e reinterpretada pelos padres da Igreja ao longo da Idade Média, sob sua ótica cristã. Caracterizados por conhecimentos enciclopédicos, pautados na descrição das coisas do mundo. Os conhecimentos cartográficos relacionados à concepção ptolomaica da Terra, 
redonda divididas em cinco zonas, foram retomados em função das navegações e exploração marítima (CARVALHO, 2006). Dessa forma, os conhecimentos geográficos presentes no ensino no Período Colonial correspondiam à Geografia clássica.

A partir da criação do Imperial Colégio de Pedro II em 1837, localizado no Rio de Janeiro, sede da antiga Corte do Império, a Geografia adquiriu o status de disciplina autônoma, embora em segunda ordem de importância, pois prevaleciam os estudos literários. Oficialmente, o colégio constituía uma escola padrão, no qual o seu currículo deveria ser seguido pelas demais escolas brasileiras. E, portanto, a Geografia passaria a compor o estudo daqueles que frequentavam o ensino formal no país (ROCHA, 1996).

Albuquerque (2012) em estudos mais recentes sobre a educação nas províncias, com base nos relatórios provinciais, demonstra que a história da disciplina é mais complexa. Em um contexto em que não havia um sistema nacional de ensino, a criação da disciplina Geografia se deu com o modelo de Cadeiras Isoladas, no ensino secundário, na Paraíba, no ano de 1831. Assim, questiona o marco histórico da fundação do Colégio Pedro como a origem da Geografia Escolar brasileira, bem como a efetiva reprodução do currículo dessa instituição nas províncias.

Para além da institucionalização formal, em relação à característica marcante desse período foi um ensino descontextualizado, distante da realidade do aluno:

Eles centravam suas abordagens sobre a Geografia geral. Nesta perspectiva, tratavam de Geografia matemática, Geografia "antiga", cosmografia e corografia. Nesta última, abordavam os continentes, dando ênfase à Europa, mas também trazendo um grande número de dados e nomenclaturas sobre a Ásia, África, América e Oceania. Alguns desses livros dedicavam-se especificamente ao estudo detalhado dos países europeus. Em linhas gerais, destacam a nomenclatura de países e principais cidades, rios e montanhas, classificações de climas, além de dados quantitativos sobre a população. (ALBUQUERQUE, 2011, p.30) 
Isto reflete uma continuidade dos conhecimentos reportados da Geografia clássica, além de representar os valores sociais da época, dado o destaque especial a Europa, em que se atribuía ser o centro difusor da civilização. Isto se traduziu na escassez de publicações nacionais ao longo do século XIX.

Segundo Albuquerque (2011), o saber geográfico relacionado ao Brasil, baseava-se na Corographia Brasílica, de Padre Manuel Aires de Casal, escrito em 1817. Resumia-se a descrição das províncias, com base em dados estatísticos e em nomenclaturas de seus aspectos, como, por exemplo, a história, limites territoriais e nomenclatura de montanhas, hidrografia, portos, cabos e pontas, mineralogia, zoologia, fitologia e algumas características de cidades e vilas. Como pode ser evidenciado a seguir em uma descrição sob o tópico de montanha na Província da Paraíba:

\begin{abstract}
MONTANHAS -- Quase todos os montes de que é semeada, são ramos da Serra da Borborema, que, (começando perto do mar dentro da Província do Rio Grande) a atravessa do nordeste ao sudoeste, ou com pouca diferença, dividindo-a em duas partes, oriental e ocidental. A derradeira, designada com o nome de Cariris Novos, e pais alto, lavado dos ventos e sadio; e também consideravelmente mais larga que a oriental (CASAL, 1817, p.274).
\end{abstract}

Percebe-se um caráter enumerativo a partir de nomenclaturas para definição deste aspecto da província. Essa consiste na maior da influência de Casal nos livros didáticos brasileiros do período, que, de acordo com Vlach (2004), serviu como referência básica para elaboração desses até as primeiras décadas do século XX.

Dentre estas obras, destaca-se 'O Compêndio Elementar de Geographia Geral e do Brasil , de Thomaz Pompeu de Sousa Brasil (1859), adotado pelo Colégio Pedro II e recomendado pelo Instituto Histórico e Geográfico Brasileiro, para o ensino da Geografia correspondente ao Brasil. Assim, constituiu o compêndio didático mais difundido no Império. Sua elaboração seguia o mesmo conteúdo e estrutura da Corographia Brasílica, sendo reproduzida com algumas alterações. Desse modo, pautou-se na mera descrição, enumeração dos fenômenos, repetição de modelos comuns à Geografia clássica (SOUZA NETO, 
2000). Essa obra foi responsável por difundir o método de ensino dialogístico, de origem jesuítica, conforme afirma Pessoa (2007):

Uma outra particularidade apresentada na obra de Pompeo é a utilização do método conhecido como dialogístico. O método se caracteriza pela elaboração de perguntas e respostas simulando um diálogo constante entre o "mestre" e o discípulo, com o objetivo de tornar mais fácil a retenção da lição pela memória. (ibidem, p.35)

Pode-se perceber que o método refletia a estrutura do processo de ensino e aprendizagem, em que a memorização constituía exigência básica para a aprendizagem. Desse modo, o aluno assumia a função de memorizar e reproduzir as diversas nomenclaturas que descreviam aspectos das províncias brasileiras. Atualmente, muitos professores, mesmo sem ter consciência de sua origem, têm suas práticas pedagógicas influenciadas por esse método de ensino.

A partir de uma análise do conteúdo, do método e dos valores sociais da época, no ensino de Geografia a natureza constituía um conjunto de informações e nomenclaturas de "acidentes geográficos". Essa expressão revela a falta de rigor científico, em que os componentes da natureza não eram explicados em sua gênese e dinâmica. Além de ministrados em uma estrutura de tópicos, privilegiando escalas continentais e em menor grau a nacional sob os recortes das províncias. Fazendo-se descontextualizado da escala local, contribuindo para o desinteresse dos alunos pela disciplina.

Sendo difícil a superação destas problemáticas metodológicas, pois aqueles que lecionavam a disciplina eram oriundos de outras formações como, por exemplo, advogados, engenheiros, médicos e seminaristas (PONTUSCHKA et al, 2009). Isto se explica pelo fato de, que naquele momento, a ciência geográfica não havia se institucionalizado academicamente no Brasil, quer dizer, não havia nem o bacharel nem o licenciado em Geografia. Diante da falta de um profissional com uma formação específica da área, favorecia-se a reprodução de práticas já presentes na cultura escolar. 
O século XIX representou importantes transformações para o Brasil, a exemplo da Independência (1822), Abolição da escravatura (1888), Proclamação da República (1889). Simultaneamente, a Geografia passava pela institucionalização na Europa, enquanto ciência moderna, bem como a sua efetiva participação na consolidação do Estado-nação mediante sua inserção no sistema de ensino formal. Desse modo, os intelectuais brasileiros da época passaram a questionar a função da disciplina de Geografia. Dentre estes, destacou-se José Veríssimo, que em sua obra 'A Educação Nacional ', em 1906:

\begin{abstract}
Apesar da pretensão contrária, nós não sabemos geografia. Nesta matéria, a nossa ciência é de nomenclatura e, em geral, cifra-se à nomenclatura geográfica da Europa. É mesmo vulgar achar entre nós quem conheça melhor essa do que a do Brasil. [...] No ensino primário brasileiro o da geografia é lamentável e, quando feito, o é por uma decoração bestial e a recitação ininteligente da lição decorada [...]. O ensino secundário é feito com vista ao exame, apressada e precipitadamente, e resume-se na enumeração e nomenclatura. [...] a geografia do País, inteligentemente compreendida e ensinada, é por assim dizer a base de toda a educação nacional bem dirigida. (VERÍSSIMO, 1985, p. 92-96)
\end{abstract}

Assim, passou-se a contestar a cientificidade do conhecimento geográfico no ensino brasileiro pautado em nomenclaturas e práticas mnemônicas. Isto refletia o progresso de institucionalização da Geografia na Europa, em que se delineavam novas orientações teórico-metodológicas distintas das praticadas no âmbito escolar brasileiro. Além disso, questiona-se a escala em que se prioriza o seu ensino.

Estas novas proposições reverberam a necessidade de consolidação do Estado- nação brasileiro, em que a Geografia é convocada a disseminar a ideologia do nacionalismo patriótico, mediante a construção de uma identidade pelo espaço (MORAES, 1991). Com isso, estimulou-se, a partir de 1870, a publicação de obras didáticas brasileiras de Geografia, ampliando no ensino os temas dedicados no Brasil (ALBUQUERQUE, 2011).

Para Vlach (2010), essa ideologia pretende forjar uma unidade nacional pautada na identidade, suprimindo as diferenças existentes e os conflitos. Nesse sentido, a Geografia com o discurso sobre o lugar cunharia uma unidade a partir 
das bases naturais. Assim, conduzia-se a despolitização dos indivíduos e, por conseguinte, a dominação de uma maioria pela minoria, com a disseminação de valores de uma classe.

Dessa forma, a Geografia Escolar clássica passa a ser questionada, sobretudo, a abordagem que privilegia uma corografia em escalas abrangentes. De modo que o ensino seja baseado no espaço próximo ao aluno e, assim, posto a serviço da construção de uma identidade nacional, não vinculada às lutas sociais, ou a evidenciar claramente como se deu a construção do território, promovendo uma identidade a-histórica com bases naturalistas, a fim de que os alunos se sentissem pertencentes a uma unidade. Com isso, a Geografia, em especial a natureza, serviu para encobrir problemáticas da sociedade.

\section{GEOGRAFIA MODERNA E NACIONALISMO: BRASIL UM “GIGANTE” PELA PRÓPRIA NATUREZA}

Na década de 1920, o Brasil passou por intensos debates, políticos e intelectuais, e reformas voltadas à organização do sistema educacional brasileiro (MATE, 2002). Assume destaque a discussão sobre o papel das disciplinas no currículo, com questionamentos sobre os programas de ensino e as metodologias adotadas pelos professores, dentre as quais destacamos a Geografia.

Inaugura-se um segundo momento para a disciplina, marcado pela introdução da Geografia moderna. O principal responsável foi Carlos Miguel Delgado de Carvalho (1884-1980), de densa formação acadêmica em importantes universidades europeias. Expoente intelectual, foi autor de livros didáticos, obras sobre o ensino de Geografa e de produção científica em Geografia. Aproximou-se dos intelectuais que defendiam os pressupostos escolanovistas, chegando a participar do "Manifesto dos Pioneiros" (1932). Este veio ao Brasil na década de 
1920 e atuou como lente do Colégio Dom Pedro II, ministrando as disciplinas de inglês e, posteriormente, Geografia e Sociologia.

Delgado de Carvalho em sua obra 'Methodologia do ensino Geographico: introdução aos estudos de Geographia Moderna` defende que a verdadeira Geografia teria como objeto de estudo a terra como habitat do homem. Dessa forma, não correspondia à Geografia ensinada no Brasil. Desenvolve críticas à ausência de teor científico e rigor conceitual, ao aspecto nomenclaturista e ao fato de constituir uma disciplina mnemotécnica. Propõe para a condução do ensino a ênfase nas regiões naturais, em substituição das unidades políticoadministrativas (CARVALHO, 1925).

Nessa obra, evidencia-se o papel da Geografia na consolidação do nacionalismo patriótico, que na época justificava sua inserção no ensino escolar, tendo o ensino da natureza um elemento preponderante em suas proposições:

\begin{abstract}
Uma das novas tendências da geographia é de se tornar cada vez mais humana nas suas investigações. O humanismo, [...] não deve excluir o conhecimento scientifico de seu habitar $<<$ habitat $>>$, das acções e reações deste $<<$ habitat $>>$ sobre as condições de vida. [...] A physiographia é pois, antes de tudo, um assumpto cujo estudo contribue á formação geral do individuo e a este criterio é que deve obedecer a seu methodo de ensino. [...] Chagámos assim á necessidade de um conhecimento mais scientifico e mais circumstanciado da geografia pátria. [...] Em todo e qualquer assumpto de geografia, em meio em que vive o alumno deve ser escolhido como assumpto principal de estudo e as noções sobre outras regiões devem ser acrescentada como informações suplementares e comparativas. (CARVALHO, 1925, p.4-6)
\end{abstract}

Para o autor o ensino dos elementos da natureza deveria ultrapassar a tradição das listas de nomenclatura de rios, relevo, bacias hidrográficas, dentre outros, bem como a descontextualização. Assim, propõe o método comparativo, de modo a ser analisado a gênese, a classificação e os exemplos mais significativos dos elementos naturais estudados, relacionando-os. $E$, principalmente, o meio em que vive o aluno se torne um princípio para o desenvolvimento dos conteúdos, de modo a despertar o interesse pela disciplina, com ênfase para o entendimento do quadro natural do território nacional. 
Delgado de Carvalho foi responsável por introduzir as orientações teóricometodológicas da Geografia moderna na Geografia escolar, uma vez que este foi o principal mentor do novo currículo prescritivo para a disciplina no Colégio Pedro II, considerada como estabelecimento de ensino padrão pelo governo brasileiro, tornada oficial a partir da reforma Luiz Alves/ Rocha Vaz no Decreto $\mathrm{n}^{\circ}$ 16. 782-A, de 13 de janeiro de 1925. A Geografia seria ensinada no primeiro, segundo e quinto ano do ensino secundário (ROCHA, 2000b).

O programa do primeiro ano se dividia em seis partes. A primeira nos estudos de herdados da Geografia clássica, tendo como temas a forma da Terra, os movimentos do planeta, a fim de se compreender as variações físicas das regiões, os estudos de orientação e coordenadas; a segunda nas lições de Geografia física que tinha o papel de promover uma análise geográfica a partir da causa dos fenômenos e sua classificação, com uso do método comparativo; Geografia política; Geografia Geral dos continentes, mediante as descrições dos aspectos naturais, a população e a economia e, por fim, o estudo das regiões naturais dos continentes. O segundo ano consistia nos estudos de Geografia do Brasil, estudando-se na sequência a fisiografia e a geologia do território, com o estudo da antropogeografia, isto é, informações sobre a população e aspectos econômicos, iniciando a segunda parte do curso com as regiões naturais brasileiras. No quinto ano, retomam-se o ensino da cosmografia e astronomia. Tais estudos deveriam se apoiar nos mapas como recurso didático (ROCHA, 2000b).

Em meio à mudança curricular, percebe-se a introdução de aspectos relacionados à Geografia moderna, sobretudo, no estudo das regiões naturais. Mas, há um conjunto de heranças quanto aos conteúdos e a sua organização. Inicia-se pelo estudo da relação Terra-Sol, importante à compreensão da diversidade de fenômenos climáticos e biogeográficos sobre a superfície terrestre, desde que os professores mobilizassem na sua prática as conexões, pois a organização dos conteúdos favorecia a fragmentação. Organizados do 
geral ao particular, conforme a progressão das séries. Além disso, Renato Jardim, na I Conferência Nacional de Educação, em 1927, afirma que:

[...] uma mal denominada Geografia Física meramente descritiva, ou, antes, "enumerativa", em que se passam em vista os acidentes físicos da região, em catalogação inútil, estudo em que se profusamente se aprendem "nomes" e não "coisas". Como fruto desse desacerto e por força da tradição, sob o pomposo título de Geografia Física (a ser estudada em seis lições!) se ostentam nos programas alíneas como este: "nomenclatura geográfica", alínea essa que claramente induz às definições costumeiras ("continente é uma vasta extensão de terra não interrompida pelo mar; ilha é uma porção de terras cercadas d'água por todos os lados"); ou esta outra alínea: "os continentes e mares", alínea que, assim expressa, evidentemente indica estudo descritivo. Não é, como devera ser, a "física terrestre" o que os programas incluem sob o nome de Geografia Física; não é, como devera ser, o estudo, no ponto de vista geral, dos fenômenos físicos que se dão na superfície da Terra, na sua interdependência de causa e efeito, e encarados como fatores do meio em que se produzem os fenômenos de natureza biológica e social, estudo esse que pode e deve ser empreendido desde o grau mais elementar e com ele proveitosamente entretidos os alunos da escola primária... (JARDIM, 1997, p. 395)

Em meio à realidade da Geografia Escolar, questionava sua correspondência quanto ao avanço científico, relacionado ao estudo da natureza na Geografia europeia. Percebe-se que esses intelectuais brasileiros tinham contato com as obras dos institucionalizados da Geografia, como Humboldt, La Blache, Ratzel, em que buscava a compreensão dos fenômenos a partir da relação entre distintos elementos. Assim, requisitava-se a escola “[...] não aquela 'ciência que trata da descrição da superfície da Terra' e sim a ciência que estuda as relações entre o Homem e a Terra" (GASPARINI, 1997, p. 43).

Diante da importância estratégica da Geografia como disciplina escolar, torna-se obrigatória na década de 1930, no governo de Getúlio Vargas, com a ênfase em um sistema nacional de ensino. De acordo com Del Gaudio (2007), a importância atribuída a Geografia escolar e, por sua vez, a natureza enquanto uma dimensão de seu objeto de estudo, colocava-se diante da:

[...] quase ausência de um mito fundador "nacional" político via história, a construção da "identidade nacional" (a partir da ação do Estado) será efetivada pelo recurso discursivo à "sua natureza". Esta permite abstrair o "povo" (em sua sociedade marcada profundamente pela escravidão) e, ao mesmo tempo, 
criar um imaginário comum capaz de conferir uma comunhão profunda entre os nacionais (a despeito de suas efetivas desigualdades). (ibidem, p. 53)

Desse modo, a Geografia foi responsável por reforçar, no sistema nacional de ensino, uma associação entre uma natureza edênica, grande extensão territorial e um povo pacífico e ordeiro, isto é, uma imagem de esperança em relação ao futuro por vir. $\mathrm{Na}$ atualidade, mesmo inconscientemente, por vezes, tal discurso é propagado nas escolas pelos professores de Geografia, bem como no cotidiano em sociedade.

Quanto à difusão das novas propostas de ensino, houve reações negativas de toda ordem e enfrentaram resistências por parte daqueles que se encontravam acomodados e satisfeitos com a situação vigente (PESSOA, 2007). Em decorrência da cultura escolar, desde a introdução da Geografia no sistema escolar. Além da sociedade que corroborava com o modelo de ensino, pois, pela tradição, compreendia as práticas mnemônicas comuns ao elenco de nomenclaturas de cunho geográfico como o que vinha a ser a Geografia Escolar. Assim, as tradições se perpetuaram no interior da escola.

Apesar das novas formulações terem sido importantes para a renovação do ensino de Geografia, até mesmo antes que a institucionalização acadêmica da Geografia, não significaram uma ruptura com o modelo vigente. Definições dos aspectos da natureza mais elaborados do ponto de vista descritivo, apoiadas no uso da cartografia para a localização, distribuição e classificação dos fenômenos estudados, passam a coexistir com metodologias que requerem do aluno a memorização.

Outro marco importante para a renovação do ensino da Geografia Escolar foi à institucionalização da Geografia em nível superior, com a criação das Faculdades de Filosofias, Ciências e Letras, na Universidade de São Paulo (1934) e a Universidade do Distrito do Federal (1935), atual Universidade Federal do Rio de Janeiro. Do ponto de vista teórico, fez-se presente à influência francesa, haja vista que para composição do quadro docente destes cursos foram convidados 
professores desta nacionalidade, a exemplo, de Pierre Deffontaines e Pierre Monbeig (ANDRADE, 1987).

Neste contexto, a existência de cursos voltados para a formação superior de profissionais em Geografia para o magistério, em sua respectiva área do conhecimento, representou um grande avanço nas transformações epistemológicas e didáticas no interior da Geografia escolar, como afirma Pontuschka et al (2009):

No Brasil, o ideário produzido pela escola francesa chegou aos bancos escolares por meio dos licenciados, mas de posse do saber científico desenvolvido na universidade e com o auxílio de livros didáticos, escritos por professores universitários, elaboravam suas aulas, produzindo um saber para os diferentes níveis de ensino. (ibidem, p.44)

Com isso, a Geografia Escolar pautada em bases modernas passa a compor as práticas de sala de aula destes novos profissionais. Porém, a quantidade de profissionais formados por esses cursos não era suficiente preencher a falta de professores licenciados para a demanda crescente. Em virtude da grande quantidade de professores sem formação atuando, segundo os princípios de uma orientação clássica, as inovações passaram a coexistir com resistências baseadas em premissas clássicas e, por sua vez, problemáticas metodológicas, como nos assegura Pessoa (2007):

[...] grande parte dos professores ainda sem formação acadêmica, não conseguia compreender satisfatoriamente as novas práticas de ensino propostas para essa disciplina. Conservavam dessa forma a velha orientação clássica, de fases ultrapassadas, porém ainda servindo de inspiração para ministração de aulas por parte de nossos educadores, o que infelizmente serviu apenas para provocar um esvaziamento do valor da geografia e do professor da própria disciplina em nossas salas de aula, relegando-a dessa forma a uma matéria de simples complementação e de cultura geral, quando não odiada pelo seu caráter descritivo e mnemônico. (ibidem, p. 57)

Um dos caminhos para a propagação da nova concepção de Geografia para o ensino, além da formação de professores, foram os livros didáticos. Neste aspecto, destacou-se Aroldo de Azevedo, professor da USP. Exerceu uma liderança intelectual sobre o ensino de Geografia em todo território nacional, tendo papel crucial na imposição do paradigma francês, visto que seus livros 
foram hegemonicamente adotados nas escolas brasileiras, atravessando gerações, entre as décadas de 1940 e 1970 do século XX (ASCENÇÃO, 2009; FURIM, 2012).

FURIM (2012) analisou quatro livros didáticos de Aroldo de Azevedo comercializados ao longo desse período. Em 'Geografia para a quarta série secundária` (1938), os conteúdos abordam os principais países do mundo e o Brasil, seguia a sequência da descrição física, superfície e população, governo, cidades principais e os recursos econômicos, na parte do Brasil e suas regiões naturais, a mesma organização. Assim, a sob a denominação de Geografia Física, estudava-se os conteúdos de relevo, costas, hidrografia, clima e recursos naturais.

Em a Geografia para a segunda série secundária` (1942) a ênfase no estudo dos continentes, sendo trazida a mesma estrutura, iniciando pelos aspectos físicos. Em 'Geografia para a quinta série do secundário `(1942) a definição dos conteúdos e a forma como são expostos assemelham-se as coleções atuais de livros didáticos destinados ao Ensino Médio, em que organizam os conteúdos relacionados à natureza, geralmente colocando-os em um único volume, o primeiro da coleção. A obra inicia com uma evolução do pensamento geográfico, passando a uma Geografia astronômica (a esfera celeste, estrelas, grupos estelares e nebulosas, sistemas planetários, o Sol, os planetas, os comentas, a Terra, movimentos da Terra, a Lua, Eclipse, a esfera terrestre, medidas de tempo e representação gráfica da Terra); a Geografia Física (estrutura da Terra, a Crosta terrestre, Eras geológicas, deslocamentos da crosta, vulcanismo, tremores, erosão e a ação dos seres vivos, aspectos do relevo, oceanos e mares, relevo submarino, águas do mar, movimentos do mar, costas, geleiras, lagos, rios, o trabalho os rios, atmosfera, ventos, climas); a Geografia Biológica (os vegetais sobre o globo, os animais sobre o globo e o homem e a natureza) (FURIM, 2012).

Em 'Geografia do Brasil: bases físicas, vida humana e econômica '(1972) a obra mantém a mesma estrutura observada em seus livros didáticos anteriores 
correspondendo às bases físicas do território brasileiro (situação geográfica, climas, vegetação, bases geológicas, relevo, litoral e ilhas oceânicas, águas continentais e oceânicas), seguida da vida humana e a vida econômica (FURIM, 2012).

A partir da organização dos conteúdos nas obras de Aroldo de Azevedo, de grande difusão no período, concordamos com Moreira (1987), em que a Geografia ensinada se caracterizou pela estrutura padrão: a natureza, o homem e a economia (arquétipo $\mathrm{N}-\mathrm{H}-\mathrm{E}$ ). Desse modo, ao ensinar um, os demais estavam ausentes, isto é, uma totalidade costurada com a soma das partes, não como um todo de significado orgânico no espaço geográfico e na relação da sociedade com o mesmo. Portanto, caracterizou-se por um discurso fragmentário, descritivo, sem conjunto e totalidade.

Portanto, disseminou-se uma metodologia positivista pautada nos preceitos da memorização de definições, na fragmentação do saber, na descrição, comparação das paisagens e suas classificações, revestidos de uma "neutralidade" política, sobreposição dos aspectos naturais e humanos. Responsável por distanciar a Geografia Escolar das grandes questões nacionais, formando alunos alheios da compreensão da realidade, apolíticos e acríticos. Portanto, a Geografia escolar contribuía para a manutenção do status quo da sociedade. Dessa forma, o ensino de Geografia se configurou neste novo momento a partir de uma interação entre as heranças existentes e as novas perspectivas.

\section{GEOGRAFIA ESCOLAR CRÍTICA: NATUREZA COMO RECURSO}

No contexto pós-Segunda Guerra, o paradigma científico e filosófico Positivista que regeu a humanidade, até então, passa a ser questionado, pois o mundo se tornou complexo a partir das profundas transformações oriundas do processo de globalização, a terceira revolução industrial, a emergência das 
questões sociais e ambientais. Desta forma, a Geografia Acadêmica é conduzida a buscar novos caminhos, por vezes distintos, considerando a divisão entre Geografia Humana e Geografia Física, aprofundada ao longo do século XX. Assim, na Geografia, os estudos da natureza encaminharam-se, sobretudo, na análise sistêmica considerando a ação antrópica, e os aspectos humanos no materialismo histórico-dialético para compreensão de um espaço social.

Com o Golpe Militar de 1964, no Brasil, medidas repressivas são impostas ao pensamento crítico, freando este movimento de contestação. A isso se acrescenta a manipulação ideológica da educação, com a finalidade de perpetuar aquela estrutura política. No tocante a Geografia Escolar, com o advento da Lei 5.692/71, esta disciplina se aglutina com a História, sob a denominação dos Estudos Sociais, que constituiu uma mera fusão das disciplinas. Isto trouxe sérios prejuízos à educação básica:

A eliminação da Geografia e da História do currículo concorreria para empobrecer a formação humanística da juventude. Comprometido de forma grave seu preparo integral e equivalente ao fracasso do ensino em si mesmo, o qual nem a Geografia, nem a História podem estar ausentes. E a adoção dos Estudos Sociais da maneira como vem sendo preconizada corresponderia a uma verdadeira supressão dos estudos geográficos e históricos em nível de $1^{\circ}$ grau. (CONTI, 1976, p. 61)

Para efetivação do projeto de despolitização da formação básica, previamente o Regime Militar se encarregou de estabelecer reformas mais amplas, incidindo na formação de professores. Com isso, foram criadas as licenciaturas em Estudos Sociais, com duração de três anos, aprovados pelo Conselho Federal de Educação em outubro de 1964. Posteriormente, ocorreu uma gradativa redução da carga horária, em que em até três meses seria possível obter uma "qualificação" para o exercício da docência, sem uma alteração no currículo. Nessa conjuntura, muitos cursos de Licenciatura plena de Geografia fecharam e deram lugar ao curso de Estudos Sociais (ROCHA, 2000a).

Essa política tinha como finalidade o enfraquecimento da formação docente, ampliando as dificuldades para lidar com os assuntos específicos da 
formação do professor de Geografia (FURIM, 2012). De modo que meramente reproduzissem o conteúdo expresso pelo livro didático, controlados sob o crivo da ditadura, em prol de um ensino produtivista, alienante e ufanista.

Nos fins dos anos 1970 o regime militar começa a entrar em crise. O modelo de educação passa a ser questionado. Professores, estudantes, instituições como a Associação de Geógrafos Brasileiros (AGB) e Associação Nacional de História (ANPUH) reivindicaram o desmembramento dos Estudos Sociais e o fim desses cursos em nível superior. No interior da escola os debates críticos passaram a se intensificar.

No contexto internacional, em meados da década de 1970, inicialmente nos Estados Unidos e na França e, posteriormente, na Espanha, Itália, Alemanha e Suíça, surgiu a(s) geografia(s) crítica(s) no âmbito acadêmico. A denominação de geografias críticas deu-se em decorrência da não uniformidade, mas que se posicionaram contrárias às tendências acadêmicas da Geografia Tradicional e da Nova Geografia pelo comprometimento com o sistema capitalista, sob a égide da falsa neutralidade.

Assim, os pressupostos desta nova corrente, pautada no materialismo histórico- dialético, consciente dos graves problemas que afligem a sociedade e, por sua vez, a produção espacial, seriam a criticidade e o engajamento, como afirma Vesentini (2004):

Pode-se dizer que os pressupostos básicos dessa "revolução" ou reconstrução do saber geográfico consistiram e consistem na criticidade e no engajamento. Criticidade como uma leitura do real - isto é, do espaço geográfico- que não omita as suas tensões e contradições, tal como fazia e faz a geografia tradicional, que ajude a esclarecer a espacialidade das relações de poder e de dominação. E engajamento visto como uma geografia não mais "neutra" e sim comprometida com a justiça social, com a correção das desigualdades socioeconômicas e das disparidades regionais. (ibidem, p. 222-223)

O novo debate se estabelece no âmbito acadêmico brasileiro apenas nos anos 1980 como paradigma predominante, retardado sua inserção em decorrência da repressão militar e da resistência da academia. Vale salientar que a penetração da nova corrente se deu através dos professores do ensino 
Fundamental e Médio, que insatisfeitos com a condição de ensino na Geografia Escolar iniciaram suas reflexões e novas abordagens e, posteriormente, sistematizaram-nas com vistas à produção de trabalhos universitários (VESENTINI, 2004).

Embora se tratasse de um pequeno grupo de professores, pode-se perceber neste momento da trajetória da Geografia Escolar, uma relação de influência da disciplina escolar em sua ciência de referência, evidenciando que esta produz um conhecimento próprio no interior da escola e não apenas reproduz os ditames da academia. Há, dessa forma, uma relação de trocas entre a disciplina escolar e a ciência de referência.

De acordo com Albuquerque (2005), no contexto da abertura política, emerge o debate de uma educação pública de qualidade e democrática. Assim, a partir da garantia do Governo Federal com o Ensino Fundamental para todos, culmina a elaboração de documentos curriculares para a organização do sistema educacional no âmbito de Estados e Municípios. Dentre estes, o Estado e Município de São Paulo na proposta curricular de Geografia adotam como método o materialismo histórico-dialético. Paulatinamente, influenciaram a elaboração de currículos por todo o Brasil.

Paralelamente a essas transformações, no contexto acadêmico se aprofundava a polêmica cisão entre professores e pesquisadores da Geografia Física e os da Geografia Humana. Os estudos da natureza representados pela Geografia Física passaram a ser criticados, sendo considerados politicamente alienados, carentes de uma reflexão política e epistemológica, um resquício da Geografia feita para instrumentalizar a ocupação e a exploração dos recursos naturais. Produziu-se um afastamento dos Geógrafos físicos dos eventos promovidos pela Associação de Geógrafos Brasileiros, organizando seus eventos específicos de Climatologia, Biogeografia, Geomorfologia, dentre outros. Como também, uma redução de sua participação na formação superior dos profissionais em Geografia (AFONSO, 2015). 
Esse embate acadêmico resultou em impactos na Geografia Escolar, considerando a participação dos acadêmicos na elaboração dos currículos e livros didáticos:

\begin{abstract}
Ao longo da década de 1980, livros didáticos reduziram os capítulos relacionados à dinâmica da Natureza, alegando a dificuldade em criar interações coerentes entre os elementos físico-naturais e os aspectos socioeconômicos e políticos e culturais da Geografia. Chegava-se mesmo a apontar as tentativas de integração como resíduos da Geografia Tradicional, associada ao reducionismo de complexidades analíticas, onde o meio físiconatural era considerado apenas como condição ou obstáculo para o desenvolvimento de um determinado grupo social. Uma evidência dessa inabilidade em integrar conteúdos da Geografia Física também se verifica em livros didáticos onde tais conteúdos passaram a ser apresentados como apêndices ou anexos do texto principal. (AFONSO, 2015, p. 39)
\end{abstract}

Diante do avanço da tendência teórica pautada no materialismo históricodialético na Geografia Escolar, os conteúdos relacionados aos componentes físico-naturais do espaço geográfico foram empobrecidos e/ou reduzidos, sob a acusação de que promoveriam a alienação dos indivíduos, como em momentos anteriores.

A discussão da natureza para compreensão do espaço consistia na concepção de uma segunda natureza, transformada e incorporada ao processo produtivo. Os componentes físico-naturais constituíam um sinônimo de recursos às atividades econômicas (água, minerais, solo, vegetação). Esse movimento exerceu duplo papel, pois de um lado favoreceu o debate sobre a relação natureza e sociedade, importante à Geografia, e de outro considerou desnecessário o reconhecimento da dinâmica da natureza nos estudos geográficos (SUERTEGARAY; ROSSATO, 2010). Portanto, o estudo da natureza em si no período da Geografia Escolar crítica foi empobrecido.

\title{
5. GEOGRAFIA ESCOLAR NO CONTEXTO DOS PCNS
}

Paralelamente, no contexto da Geografia acadêmica, outra corrente se desenvolveu nos anos de 1970, posicionando de maneira crítica aos paradigmas vigentes. A chamada Geografia Humanística ao pautar-se no método 
fenomenológico, interessa-se pelo mundo vivido que congrega as subjetividades dos sujeitos, as percepções, comportamentos, os sentimentos que os indivíduos desenvolvem diante da experiência com o espaço, tendo como conceitos fundamentais as categorias espaço, paisagem e lugar. Nos anos 1990 adquire maior amplitude ao incorporar a cultura, as representações e seus significados materializados no espaço geográfico (SUERTEGARAY, 2005).

Esta corrente exercerá influências na Geografia escolar a partir da década de 1990, com a elaboração de um currículo prescritivo de âmbito nacional, os chamados Parâmetros Curriculares Nacionais (PCNs) direcionados ao Ensino Fundamental e Ensino Médio. Fundamentando o ensino de Geografia em uma perspectiva fenomenológica e nas teorias pedagógicas construtivistas, valorizando a maneira que os alunos apreendem o espaço, isto é, os conhecimentos prévios dos alunos.

No entanto, não constituía o único paradigma teórico utilizado na elaboração do documento. Para Oliveira (1999) os PCNs constituem um documento eclético, haja vista que nele coexistem múltiplas possibilidades para a compreensão do espaço, desde a Geografia Crítica, Geografia Humanística e o positivismo clássico. Nesta última, afirma que a lógica própria da natureza é abordada a partir da compartimentação:

Planeta Terra: a nave em que viajamos.

Como o relevo se forma: os diferentes tipos do relevo.

Litosfera e movimentos tectônicos: existem terremotos no Brasil?

As formas de relevo, os solos e sua ocupação: urbana e rural.

Erosão e desertificação: morte dos solos.

As águas e o clima. [...] (PCNS, 1998, p.63-64)

O espaço geográfico é destacado como objeto de estudo da Geografia Escolar. Para compreendê-lo a relação sociedade e natureza é fundante. Assim, a abordagem da natureza é retomada em nível de currículo, guardando aspectos na organização dos conteúdos de forma similar a períodos anteriores. Embora 
seja ampliada a concepção de natureza, em relação os currículos e livros didáticos da década de 1980:

A natureza tem seus mecanismos e leis que podem ser estudados em sua regularidade e tempos próprios. O estudo do funcionamento da natureza pode ser encaminhado a partir de problematizações de fatos da atualidade, contextualizados a partir do cotidiano do aluno. Sugere-se que o professor proponha os itens considerando a possibilidade de trabalhar os componentes da natureza, sem fragmentá-los, ou seja, apresentando-os de forma que mostre que na natureza esses componentes são interativos. [...] é muito importante mostrar nos estudos de Geografia da natureza como ela acontece independentemente das ações de uma sociedade, ao mesmo tempo que se pode discutir como ela vem sendo modificada pelas alterações ambientais produzidas pelas diferentes sociedades. (BRASIL, 1998, p. 62)

Com isso, a Geografia Escolar congrega componentes físico-naturais e sociais na condição de conteúdos de ensino que, a partir da mediação do professor, devem operacionalizar leituras da realidade. Contudo, os componentes físico-naturais, isto é, aqueles que se originam independente da ação antrópica, mas que ao mesmo tempo no estágio atual de desenvolvimento técnico não pode ser desconsiderada sua relação com a sociedade, haja vista a origem de inúmeras consequências, por vezes, negativas. Portanto, coloca-se na Geografia Escolar no âmbito do currículo, a importância de considerar a dinâmica da natureza em si e desta com a sociedade.

Os conceitos geográficos de lugar, paisagem, território, região e ambiente são requisitados para a abordagem dos conteúdos, a fim de propiciarem diferentes perspectivas de leituras do espaço geográfico. Com destaque especial para os conceitos de lugar, paisagem e ambiente no ensino dos elementos que compõe a natureza, diante das orientações de valorizar o contexto em que os alunos estão inseridos, em suas dimensões vividas e percebidas, de modo que construa uma compreensão crítica dos problemas ambientais.

Isso promoveu algumas transformações nos materiais didáticos que após a divulgação desses documentos, que seguem em parte suas orientações, apresentando na maioria dos casos a expressão "De acordo com os PCNs". Sobretudo, por passarem pela avaliação do Programa Nacional do Livro Didático 
(PNLD), a fim de serem distribuídos gratuitamente nas escolas públicas, inicialmente do Ensino Fundamental, em seguida também o Ensino Médio (ALBUQUERQUE, 2014).

Desse modo, ocorreu uma difusão de mudanças propostas nos PCNs por meio dos livros didáticos, ao tratar temas mais atuais, em função dos avanços científicos na Geografia Acadêmica, com ênfase nos problemas ambientais.

No entanto, ainda persistem, em parte dos livros do ensino fundamental, uma influência e uma permanência da forma clássica e compartimentada de compreender e ensinar a natureza; uma negação do conhecimento da natureza em sua dinâmica e, em muitos casos, um abandono ou minimização dessa temática, considerando que o que importa à geografia é a produção do espaço, ou o espaço construído. (SUERTEGARAY; ROSSATO, 2010, p.155)

Tais permanências na Geografia Escolar reproduz a dicotomia entre Geografia Física e Geografia Humana (MORAIS, 2011). No Ensino Médio as permanências também podem ser identificadas. Furim (2012) ao analisar livros três livros didáticos publicados em 2012 identificou a concentração dos conteúdos referente à natureza no primeiro ano do Ensino Médio, reproduzindo uma estrutura de conteúdos semelhantes aos livros didáticos de Aroldo de Azevedo.

As permanências não se resumem a fragmentação dos conteúdos, há permanências do ponto de vista conceitual. Pesquisas com ênfase nos conhecimentos docentes, como a de Morais (2011) para o ensino do relevo, rochas e solo, identificaram tais conteúdos são tratados no ensino como algo estanque, desvinculado das relações entre a sociedade e a natureza, e da realidade vivida e percebida. De acordo com Ascenção (2009), em relação ao ensino do relevo:

O paradigma de referência para a abordagem do relevo é o regional, o que explica a presença privilegiada das macroformas e o distanciamento de uma abordagem que considere o relevo local. A paisagem, categoria de análise do espaço considerada fértil para o trabalho, nesse segmento educativo, não pode ser trabalhada a partir da dimensão do vivido, pois a escala espaçotemporal assumida para abordagem do relevo trata de formas e processos que o olhar não alcança (ibidem, 2009, p.123). 
A autora discute que a forma como o relevo é ensinado remonta as dimensões regionais, com gênese na Geografia moderna, que se destacam os conceitos de Planície, Planaltos e Depressões, difundidos a partir dos livros didáticos de Aroldo de Azevedo. Logo, fazem-se presente nos conhecimentos docentes e nos livros didáticos tais permanências, que se contrapõem ao potencial do ensino do relevo, diante das proposições no ensino de Geografia, pois necessita de um elevado nível de abstração, dificultando a compreensão pelos discentes de suas influências no processo de organização espacial e, tampouco, na vida cotidiana.

Portanto, há desafios que perpassam o ensino e aprendizagem, pois, conforme Cavalcanti (2010), os professores têm dificuldades de trabalhá-los com base nos referenciais cotidianos dos discentes, pautando-se no livro didático de maneira acrítica e naturalista. Em contraposição, assim, com a ampliação das propostas para abordagem dos componentes fisíco-naturais em trabalhos acadêmicos.

\section{DEMANDAS CONTEMPORÂNEAS PARA O ENSINO DOS COMPONENTES FÍSICO-NATURAIS DO ESPAÇO GEOGRÁFICO}

$\mathrm{Na}$ atualidade, constatam-se aspectos que constituem permanências produzidas ao longo da trajetória da natureza na Geografia Escolar. Geralmente, o ensino de conteúdos como o clima, as rochas, o relevo, a hidrografia, a vegetação, os solos, dentre outros, são reduzidas a descrições estanques, classificações isoladas, nomenclaturas, desarticulados da sociedade, como também um distanciamento do contexto vivenciado pelos discentes. Com isso, ampliou-se nos últimos anos reflexões teórico-metodológicas e propostas para o ensino da natureza na Geografia Escolar, tanto no campo da Didática da Geografia, quanto nas propostas curriculares. 
No âmbito acadêmico, têm sido desenvolvidas em nível de Pós-Graduação stricto sensu (Mestrado e Doutorado), como, por exemplo, em Morais (2011), Mendes (2017), Paixão (2018), Novais (2018), dentre outros. Dentre estas pesquisas, ressalta-se a utilização do termo "físico-natural" para indicar os componentes da natureza (clima, relevo, vegetação, dentre outros), a fim de justificar que no ensino de Geografia não há o ensino de Climatologia, Geomorfologia, Pedologia, dentre outras subáreas da especialização da Geografia Acadêmica, isto é, há apenas Geografia, enquanto disciplina escolar, cujo objeto de estudo é o espaço geográfico.

Há uma compreensão da indissociabilidade da dinâmica dos componentes físico-naturais em conexão, isto é, dos elementos formadores do Planeta em que sua gênese independe da ação do trabalho humano, e da dinâmica resultante da relação com a sociedade, diante do atual estágio intervenção técnica.

Desse modo, há uma discussão escalar espaço-temporal. A escala temporal valorizada em tais produções acadêmicas é o tempo da história, não apenas do tempo geológico, da formação do Planeta. Em relação à escala, valoriza-se a do local, de modo em que se buscam as conexões entre os componentes físiconaturais e sociais, bem com outras escalas. E, com isso, haja uma relevância social no ensino dos componentes físico-naturais ao elucidar problemas ambientais que afetam a qualidade de vida dos alunos e de sua comunidade.

Nesse debate há uma compreensão dialética da natureza com a sociedade para constituição do espaço, isto é, uma abordagem que busca a superação da relação dicotômica. Natureza e espaço partem do princípio de uma compreensão totalizante. Busca-se a unidade do real, por meio de sistema de produção e as forças produtivas que dotam a natureza de uma existência social, resgatando as dialeticidades das relações processuais que se materializam na paisagem. Tornase necessário, assim, compreender os fenômenos em sua integridade (o mundo não pode ser analisado a partir de elementos isolados), buscando suas conexões locais e não locais a fim de entender o espaço (CASSETI, 2009). 
No âmbito das propostas curriculares, com destaque para a Base Nacional Comum Curricular (BNCC) do Ensino Fundamental, que corrobora com a compreensão que os alunos(as) precisam fazer a leitura do mundo mediante o raciocínio geográfico, de modo a "conhecer os fundamentos naturais do planeta e as transformações impostas pelas atividades humanas na dinâmica físico-natural, inclusive no contexto urbano e rural". (BRASIL, 2017, p.264). Aqui se ressalta os conceitos estruturantes do pensamento geográfico, com destaque para os conceitos de natureza e ambiente.

Suertegaray (2018) ao analisar tal currículo, corroborando com as discussões da distinção entre a Geografia Escolar e Geografia Acadêmica, propõe o estudo da natureza (e não da Geografia Física) na Educação Básica. A proposta é ensinar a natureza, enquanto uma dimensão constituinte do espaço geográfico, assim, propõe que:

[...] devemos buscar um caminho que, sem abandonar a descrição e a classificação, a análise se amplie, de forma que nossos alunos compreendam que elementos da natureza, para serem reconhecidos, precisam ser identificados, localizados, nominados, descritivos, agrupados, e na continuidade, explicados na sua origem e na sua dinâmica. (SUERTEGARAY, 2018, p. 16)

Com isso, não se trata de ignorar todas as permanências na abordagem da natureza na Geografia Escolar, haja vista que a autora ressalta aspectos importantes para o desenvolvimento do pensamento geográfico dos discentes para compreensão da natureza em sua origem e dinâmica. Sendo necessário em uma análise geográfica, estabelecer as conexões com os processos de intervenção e transformação pela sociedade. De modo que os alunos sejam capazes de interpretar uma dada situação geográfica, mobilizando princípios do raciocínio geográfico como localização, extensão, distribuição, diferenciação, conexão e analogia.

Até então, tais discussões acadêmicas e proposições curriculares não evidenciam a realidade concreta na sala de aula, mas projeções. Constituindo desafios à formação de professores de Geografia, nos cursos de licenciatura. De 
modo que na formação inicial busque-se uma formação científica consistente, ao mesmo tempo em que proponha um direcionamento pedagógico, fundamentado à luz das discussões do campo do ensino de Geografia e, consequentemente, das demandas da atuação profissional docente.

\section{CONSIDERAÇÕES FINAIS}

A partir do exposto, entende-se que, ao longo da história da Geografia Escolar, a natureza sempre este presente na composição dos conteúdos escolares sob diferentes concepções nos manuais didáticos e propostas curriculares: nomenclaturas de "acidentes geográficos", palco para as atividades humanas, reduzida a recursos naturais, como primeira e segunda natureza.

No entanto, considera-se a existência de continuidades, mesmo quando há introdução de novas orientações teórico-metodológicas a partir da ciência de referência na formação dos professores, nos materiais didáticos e nos currículos. Isso ocorre porque as transformações na Geografia Escolar não se dão por mera transposição didática dos conhecimentos produzidos na universidade à escola, mas em meio a uma cultura escolar produzida no decorrer de sua história. Explicando, assim, a manutenção de conteúdos, conceitos e metodologias de ensino, que não correspondem às demandas contemporâneas para o ensino dos componentes físico-naturais do espaço geográfico.

A partir da análise da trajetória da natureza na Geografia escolar, percebese que os percalços que afetam suas contribuições à formação dos alunos(as) ainda se fazem presentes. Tais percalços como o ensino descontextualizando do lugar de vivência, com elevada abstração, sem articulação às questões sociais, desinteressante aos alunos(as), dentre outros, são oriundos de momentos passados, mas que consistem em permanências em meio às mudanças na Geografia Escolar. Mas, é possível a elaboração de metodologias de ensino que ultrapassem esses desafios, de modo que o estudo da realidade do lugar dos 
alunos seja considerado em prol da construção do conhecimento pautado na criticidade, autonomia e criatividade, diante dos problemas socioambientais vivenciados.

Portando, a formação inicial do professor de Geografia deve propiciar reflexões sobre as permanências no ensino dos componentes físico-naturais. E, com isso, os licenciandos munidos de conhecimentos teórico-metodológicos e didático-pedagógicos, fundados sua ciência de referência, com ênfase nos componentes curriculares relacionados ao estudo da natureza, possam em seu futuro exercício profissional desenvolver reflexões e propostas metodológicas que corroborem com um tratamento crítico dos componentes físico-naturais do espaço geográfico.

\section{REFERÊNCIAS}

AFONSO, A. E. Perspectivas e Possibilidades do Ensino e da Aprendizagem em Geografia Física na formação de professores. 2015. 263 f. Tese (Doutorado em Geografia), Universidade Federal do Rio de Janeiro, Rio de Janeiro.

ALBUQUERQUE, M. A. M. de. Currículos de Geografia: da abertura política aos PCN's. Mercator, Fortaleza, n. 07, ano 04, p. 57-74, 2005.

ALBUQUERQUE, M. A. M. de. Dois momentos na história da Geografia escolar: a Geografia clássica e as contribuições de Delgado de Carvalho. Rev. Bras. Educ. Geog., Rio de Janeiro, v. 1, n. 2, p. 19-51, jul./dez., 2011.

ALBUQUERQUE, M. A. M. de. Um debate acerca da origem da Geografia escolar no Brasil. In. III Encontro Nacional de História do Pensamento Geográfico. I Encontro Nacional de Geografia Histórica. Rio de Janeiro. Anais... Rio de Janeiro, UFRJ, 2012.

ALBUQUERQUE, M. A. M. de. Livros didáticos e currículos de Geografia, pesquisas e usos: uma história a ser contada. In. TONINI, I. M. et. al. (Orgs.). O ensino de Geografia e suas composições curriculares. v.1. Porto Alegre: Editora Mediação, 2014. p. 161-174.

ANDRADE, M. C. Geografia, ciência da sociedade: uma introdução à análise do pensamento geográfico. São Paulo: Atlas, 1987. 
ASCENÇAO, V. O. R. Os conhecimentos docentes e a abordagem do relevo e suas dinâmicas nos anos finais do Ensino Fundamental. 2009. 150 f. Tese (Doutorado em Geografia), Universidade Federal de Minas Gerais, Belo Horizonte.

BRASIL. Parâmetros Curriculares Nacionais. BRASÍLIA: MEC. 1998.

BRASIL. Base Nacional Comum Curricular. Educação Infantil e Ensino Fundamental. BRASÍLIA: MEC. 2017.

CASAL, M. A. Corografia Brasílica. Rio de Janeiro: Imprensa Regia, 1817.

CASSETI, V. A natureza e o espaço geográfico. In: Mendonça, F. KOZEL, S. (Orgs.). Elementos de Epistemologia Contemporânea. 1 ed. rev. Curitiba: Ed. da UFPR, 2009, 145-163.

CARVALHO, D. de. Methodologia do Ensino Geographico- Introdução aos Estudos de Geografia Moderna. Tomo I. Petrópolis, RJ: Typographia das Vozes, 1925, p. 03-35.

CARVALHO, M. S. de. A Geografia na Idade Média. In: A Geografia desconhecida. Londrina: EDUEL, 2006.

CAVALCANTI, L. de S. Concepções teórico-metodológicos da Geografia Escolar no mundo contemporâneo e as abordagens no ensino. In: SANTOS, L. L. de. C. P. et. al. Convergências e tensões no campo da formação e do trabalho docente. Belo Horizonte: Autêntica, 2010, p. 386-391.

CHERVEL, A. História das disciplinas escolares: reflexões sobre um campo de pesquisa. Teoria \& Educação, v. 2, 177-229, 1990.

CONTI, J. B. A reforma do ensino de 1971 e a situação da Geografia. Boletim Paulista de Geografia, São Paulo, n.51, 1976, jun. p. 57-73.

DEL GAUDIO, R. S. Ideologia nacional e discurso geográfico sobre a natureza brasileira. Lutas Sociais, (PUCSP), v. 17/18, p. 48-63, 2007.

FURIM, A. de F. R. O ensino de Geografia Física no Ensino Médio: qual seu lugar? 2012. 162 f. Dissertação (Mestrado em Geografia), Universidade de São Paulo, São Paulo.

GASPARINI, I. S. O Brasil carece da difusão do ensino popular da Geografia. In. COSTA, M. J. F. da; SHENA, D. R. SCHMIDT, M. .A. I Conferência Nacional de Educação -Curitiba, 1927. BRASÍLIA: INEP, 1997, p. 41-46.

JARDIM, R. O ensino da Geografia: necessidade de uma reforma de programas e métodos. In. COSTA, M. J. F. da; SHENA, D. R. SCHMIDT, M. A. In: I Conferência Nacional de Educação, Curitiba, 1927. BRASÍLIA: INEP, 1997, p. 388-399. 
MATE, C. H. O discurso reformista na educação brasileira. In. Mate, C. H. Tempos modernas na escola: os anos 30 e a racionalização da educação brasileira. Bauru: EDUSC, Brasília: INEP, 2002, p. 33-74.

MENDES, S. de O. O solo no Ensino de Geografia e sua importância para a formação cidadã na Educação Básica. 2017. 160f. Dissertação (Mestrado em Geografia)- Universidade Federal de Goiás, Goiânia.

MORAES, A. C. R. Notas sobre identidade nacional e institucionalização da Geografia no Brasil. In. Estudos Históricos, Rio de Janeiro, v. 4, n. 8, 1991, p. 166-176.

MORAIS, E. M. B. O ensino das temáticas físico-naturais na Geografia Escolar. 2011. 309 f. Tese (Doutorado em Geografia). Universidade de São Paulo, São Paulo.

MOREIRA, R. O discurso do avesso (para a crítica da Geografia que se ensina). Rio de Janeiro: Dois Pontos Editora Ltda. 1987.

NOVAIS, G. S. de. O ensino do relevo na Geografia escolar: contribuições para a abordagem das microformas. 2018. 186f. Dissertação (Mestrado)- Universidade Federal de Goiás, 2018.

OLIVEIRA, A. U. de. Geografia e Ensino: os Parâmetros Curriculares Nacionais em discussão. In. CARLOS, A. F. de A.; OLIVEIRA, A.U. de. Reformas no Mundo da Educação: Parâmetros Curriculares de Geografia. São Paulo: contexto, 1999, p.43-67.

PAIXÃO, T. N. O ensino do componente físico-natural clima na Geografia escolar: a escala como fundamento conceitual. 2018. 137f. Dissertação (Mestrado em Geografia). Universidade Federal de Goiás, Goiânia.

PESSOA, R. B. Um olhar sobre a trajetória da geografia escolar no Brasil e a visão dos alunos de ensino médio sobre a geografia atual. 2007.130p. Dissertação (Mestrado em Geografia). Universidade Federal da Paraíba, João Pessoa.

PONTUSCHKA, N. N.; PAGANELLI, T. I; CACETE, N. H. Para ensinar e Aprender Geografia. São Paulo: ed. Cortez, 2009.

ROCHA, G. O. R. Uma breve história da formação do (a) professor (a) de Geografia no Brasil. Terra Livre, n.15, 2000 a, p. 129-144.

ROCHA, G. O. R. Delgado de Carvalho e a Orientação Moderna no Ensino da Geografia Escolar Brasileira. Terra Brasilis, Rio de Janeiro, v. 1, p. 2000b, p. 1-16.

ROCHA, G. O. R. da. A trajetória da disciplina Geografia no currículo escolar brasileiro (1839 - 1942). 1996. Dissertação (Mestrado em Educação e Currículo)Pontifícia Universidade Católica, São Paulo. 
SOUSA NETO, M. F. O compêndio Elementar de Geografia Geral e Especial do Brasil. Terra Brasilis, Rio de janeiro, v. 1. n. 1, p. 08-51, 2000.

SUERTEGARAY, D. M. A. Notas sobre a epistemologia em Geografia. Cadernos Geográficos, Florianópolis, n. 12, p. 1-63, Maio, 2005.

SUERTEGARAY, D. M. A.; ROSSATO, M. S. Natureza: concepções no ensino fundamental de Geografia. In: BUITONI, M. M. S. Geografia: ensino fundamental. Brasília: Ministério da Educação, Secretária de Educação Básica, 2010. p. 151-164.

SUERTEGARAY, D. M. A. Geografia Física na Educação Básica ou o que ensinar sobre natureza em Geografia? In: MORAIS, E. M. B. de; ALVES, A. O.; ASCENÇÃO, V. de O. R. (Org.). Contribuições da Geografia Física para o ensino de Geografia. Goiânia: C\&A Alfa Comunicação, 2018. p. 13-32.

VERÍSSIMO, J. A Educação Nacional. 3ª ed. Porto Alegre: Mercado aberto, 1985.

VESENTINI, J. W. Realidade e perspectivas no ensino de Geografia no Brasil. In: VESENTINI, J. W. (Org.). O ensino de Geografia no século XXI. Campinas: Papirus, 2004. p. 219-248.

VLACH, V. R. F. O ensino de Geografia no Brasil: uma perspectiva histórica. In. VESENTINI, J. W. (Org.). $O$ ensino de Geografia no século XXI. Campinas, SP: Papirus, 2004. p. $187-218$.

VLACH, V. R. F. Ideologia do nacionalismo patriótico. In: OLIVEIRA, A. U. (Org.). Para onde vai o ensino de Geografia? 9a ed. São Paulo: Contexto, 2010. p. 39-45. 